\title{
Scenario and modelling uncertainty in global mean temperature change derived from emission-driven global climate models
}

\author{
B. B. B. Booth ${ }^{1}$, D. Bernie ${ }^{1}$, D. McNeall ${ }^{1}$, E. Hawkins ${ }^{2}$, J. Caesar ${ }^{1}$, C. Boulton ${ }^{1,3}$, P. Friedlingstein ${ }^{4}$, and \\ D. M. H. Sexton ${ }^{1}$ \\ ${ }^{1}$ Met Office Hadley Centre Fitzroy Road, Exeter, EX1 3PB, UK \\ ${ }^{2}$ National Centre for Atmospheric Science, Department of Meteorology, University of Reading, Reading, UK \\ ${ }^{3}$ College of Life and Environmental Sciences, University of Exeter, Hatherly Laboratories, Prince of Wales Road, \\ Exeter, EX4 4PS, UK \\ ${ }^{4}$ College of Engineering, Mathematics and Physical Sciences University of Exeter, Harrison Building, North Park Road, \\ Exeter, EX4 4QF, UK
}

Correspondence to: B. B. B. Booth (ben.booth@metoffice.gov.uk)

Received: 1 August 2012 - Published in Earth Syst. Dynam. Discuss.: 7 September 2012

Revised: 27 February 2013 - Accepted: 4 March 2013 - Published: 8 April 2013

\begin{abstract}
We compare future changes in global mean temperature in response to different future scenarios which, for the first time, arise from emission-driven rather than concentration-driven perturbed parameter ensemble of a global climate model (GCM). These new GCM simulations sample uncertainties in atmospheric feedbacks, land carbon cycle, ocean physics and aerosol sulphur cycle processes. We find broader ranges of projected temperature responses arising when considering emission rather than concentration-driven simulations (with 10-90th percentile ranges of $1.7 \mathrm{~K}$ for the aggressive mitigation scenario, up to $3.9 \mathrm{~K}$ for the high-end, business as usual scenario). A small minority of simulations resulting from combinations of strong atmospheric feedbacks and carbon cycle responses show temperature increases in excess of $9 \mathrm{~K}$ (RCP8.5) and even under aggressive mitigation (RCP2.6) temperatures in excess of $4 \mathrm{~K}$. While the simulations point to much larger temperature ranges for emission-driven experiments, they do not change existing expectations (based on previous concentration-driven experiments) on the timescales over which different sources of uncertainty are important. The new simulations sample a range of future atmospheric concentrations for each emission scenario. Both in the case of SRES A1B and the Representative Concentration Pathways (RCPs), the concentration scenarios used to drive GCM ensembles, lies towards the lower end of our simulated
\end{abstract}

distribution. This design decision (a legacy of previous assessments) is likely to lead concentration-driven experiments to under-sample strong feedback responses in future projections. Our ensemble of emission-driven simulations span the global temperature response of the CMIP5 emissiondriven simulations, except at the low end. Combinations of low climate sensitivity and low carbon cycle feedbacks lead to a number of CMIP5 responses to lie below our ensemble range. The ensemble simulates a number of highend responses which lie above the CMIP5 carbon cycle range. These high-end simulations can be linked to sampling a number of stronger carbon cycle feedbacks and to sampling climate sensitivities above $4.5 \mathrm{~K}$. This latter aspect highlights the priority in identifying real-world climatesensitivity constraints which, if achieved, would lead to reductions on the upper bound of projected global mean temperature change. The ensembles of simulations presented here provides a framework to explore relationships between present-day observables and future changes, while the large spread of future-projected changes highlights the ongoing need for such work. 


\section{Introduction}

There are important unknowns both in how we understand the current climate system and future socio-economic change, which lead to a broad spread in future projected global mean temperature changes (Cox and Stephenson, 2007; Hawkins and Sutton, 2009). The unknowns external to the climate processes relate to different future pathways of population change, economic growth, technology development and energy use (Nakicenovic et al., 2000), while uncertainties in climate feedbacks (Knutti and Hegerl, 2008; Collins et al., 2011) and carbon cycle processes (Friedlingstein et al., 2006; Booth et al., 2012a) alongside processes which drive natural variability (Lee et al., 2006) lead to differences in how the climate responds to these socio-economic changes. On short lead times (10-15 yr) internal variability represents a large fraction of the total uncertainty, with the uncertainties in model response becoming more dominant as the anthropogenic signal increases through the 21 st century. By the end of the century, differences in socio-economic pathways which diverge from present-day, dominate the global mean temperature spread. Yet much of our existing information on how these uncertainties play out is based on general circulation models (GCMs), driven by future changes in atmospheric greenhouse gas concentrations (Hawkins and Sutton, 2009), a framework that explicitly ignores uncertainties in carbon cycle processes (Friedlingstein et al., 2006), which relate emissions to global concentrations. As a result, emission-driven projections have largely relied on simpler modelling frameworks and to date, no study has explored future global mean temperature uncertainty from the emission-driven paradigm, using ensembles of full carbon cycle GCMs.

GCMs and Earth system models (ESMs) form the top of the hierarchy of climate modelling tools. The driving motivation behind these models is to represent the climate at a process level. The response of these models to differences in future socio-economic pathways is an emergent, rather than a prescribed property, which results from the interaction of climate processes with the future concentration (GCM) or emission (ESM) changes. In contrast, computationally faster climate simulation tools prescribe the magnitude of the response for some or all climate components (often calibrated against the emergent GCM/ESM simulation responses). GCMs/ESMs are computationally very expensive to run (with some state-of-the-art configurations capable of taking more than a year to simulate 240 climate model years) and so there are limited realisations of these models available. Increasingly we see ESMs incorporating processes controlling the exchange of carbon around the climate system, which are capable of being driven directly by emissions, rather than relying on future concentration pathways. However, these remain a minority of available simulations.

Due to these computational limits on the numbers of GCM simulations, much current climate projection information is provided using simpler model frameworks which rely on global energy balance assumptions to constrain the range of future changes. At the simplest level these relate changes in climate forcing to global mean temperature change based on assumptions about the nature of the ocean heat uptake and sensitivity of climate feedbacks, but more commonly are capable of translating global emission changes into concentrations and therefore global temperatures. These relationships form the basis of simple climate models (SCMs) and even some Earth system models of intermediate complexity (EMICs), which in turn are often used as the climate component of integrated assessment models (IAMs). These model frameworks enable much more exhaustive sampling of possible future projections based on different emission scenarios, and are capable of rapidly sampling uncertainties in the responses. For example, the future projection advice in the last IPCC assessment report used an SCM to synthesise the information on future projections (Fig. 10.26, WG1 SPM IPCC, 2007). Similarly, Murphy et al. (2009) make use of an SCM to capture the response of a number of GCM experiments designed to sample different climate uncertainties, and provide projection information based on how these processes combine within the SCM. Credibility of projections using these tools arises from their ability to capture the range of different future responses of a particular GCM, using a single SCM configuration. While many of these tools provide only information on global mean temperature, models on the more complex end of this spectrum (such as EMICs) often extend these approaches to include spatial scales and other variables.

Here, in a complementary approach to the multi-model GCM assessments of climate uncertainties, we make use of a new ensemble of simulations which samples uncertainty within a single coupled climate model GCM (HadCM3C) using a perturbed physics or perturbed parameter approach. Murphy et al. (2004) demonstrated that uncertainties in the physical model's atmospheric and surface parameters could account for a very large fraction of the uncertainty in Climate Sensitivity (the amount the climate would be expected to warm in response to a doubling of $\mathrm{CO}_{2}$ ). Since then similar perturbations to the atmosphere-ocean configuration of this model have been used to explore uncertainties in transient climate change (Collins et al., 2006, 2011). This approach has been extended to look at ocean physics uncertainty (Collins et al., 2007; Brierley et al., 2010) and the land carbon cycle (Booth et al., 2012a). In this latter study, Booth et al. (2012a) noted that the uncertainty in future climate projections arising from land carbon cycle processes contributed comparably to future projection uncertainty as atmospheric feedbacks. The impact of these uncertainties and their interactions, together with perturbations to the sulphur cycle, were explored within a single 57-member ensemble (Lambert et al., 2013) for a central SRES scenario, A1B.

Here we present a further two experiments which extend the future projections from this ensemble of HadCM3C simulations to encompass a high-end business as usual scenario 
and a scenario for future emissions under aggressive mitigation. These simulations enable us to explore some of the implications for projections, arising from uncertainties in the modelling components. They also mean we can compare climate responses with CMIP5 models, directly, as emissiondriven CMIP5 simulations are available for one of these two scenarios. Here we reassess what these uncertainties imply for future changes in atmospheric $\mathrm{CO}_{2}$ and global mean temperature, when considered from the perspective of emissions driven scenarios (as opposed to atmospheric concentration) where the full effect of carbon cycle feedbacks are expressed. At the high-end, these simulations complement the new CMIP5 RCP8.5 emission-driven simulations. For the central SRES A1B and the aggressive mitigation scenario (RCP2.6), these simulations represent a unique sampling of emission-driven uncertainty in ESMs.

\section{Ensembles and data}

\subsection{Perturbed parameter ensembles of HadCM3C}

The model which underpins these ensembles (HadCM3) has been in use for over $10 \mathrm{yr}$. The spatial resolution is coarser than a number of more recent models but still performs credibly (relative to multi-model GCMs) when compared to observed climate (Reichler and Kim, 2008). The relatively lower resolution means that the computational cost of running a number of versions of the model (an ensemble) to explore uncertainty is affordable. This is what is done here using HadCM3C, a coupled carbon cycle configuration (described in Booth et al., 2012a) of the Atmospheric-Oceanic version, HadCM3 (Collins et al., 2011).

The framework presented here is the culmination of previous experiments to explore the uncertainty in future climate projections, using ensembles of GCM simulations, which each sample plausible model variants in a different Earth system component (Murphy et al., 2007). There were 4 previous ensembles of HadCM3 (each with 17 members) which sampled uncertain parameters in the land and atmospheric physics, land carbon cycle, ocean physics and aerosol sulphur cycle, respectively. The original atmospheric ensemble explored parameter uncertainty in convection, radiation, gravity wave drag, dynamics, boundary layer and land surface parameterisations (Collins et al., 2011); the ocean physics ensemble explored mixed layer, vertical mixing, advection and eddy mixing parameterisations (Collins et al., 2007); The sulphur cycle physics ensemble explored parametric uncertainty in sulphate formation and removal pathways and direct scattering properties (discussed in Murphy et al., 2007; Lambert et al., 2013). The land carbon cycle ensemble explored parameters involved in plant competition, temperature controls on photosynthesis and respiration, leaf nitrogen, sensitivity to $\mathrm{CO}_{2}$ change and soil moisture controls on evapotranspiration (Booth et al., 2012a).
These 4 separate ensembles give us 4 different sets of 17 parameter combinations, from which we construct a single ensemble of Earth system model simulations that explores how uncertainties in the 4 separate Earth system components interact. The details about the experimental design of this ensemble for the A1B SRES scenario can be found in Lambert et al. (2013) but here we briefly describe the main points. The first constraint on the experimental design was that we could only afford to run an ensemble of $68 \mathrm{mem}-$ bers. To sample a broad range of combinations and minimise the correlations between pairings of individual Earth system components, the 68-member ensemble was generated using four 17-member Latin Hypercube designs. This means that each of the 17 parameter combinations for each of the 4 individual Earth system components appears 4 times in the 68member ensemble. Each of the 68 members was spun up to achieve a pre-industrial (1860) stable climate control state (temperature drifts per $100 \mathrm{yr}$ less than $0.01 \mathrm{~K}$ and net carbon fluxes into the land or ocean less than $0.4 \mathrm{GtC} \mathrm{yr}^{-1}$ ). To avoid running scenario simulations for any model variant deemed grossly unrealistic in its control state, we rejected ensemble members based on the following three criteria. First, we required models with control states that had top of atmosphere radiative imbalance no greater than found in the previous atmospheric physics ensemble (Collins et al., 2011) and all 68 members passed. The second criterion rejected 10 models where either tropical or boreal forests were largely absent. Thirdly, one simulation was rejected as it had formed an ice world with 1860 boundary conditions (with global temperatures $10^{\circ}$ below 1860 values). This left 57 simulations which were subsequently run on to simulate the historical and future scenarios presented here. We will refer to this resulting 57 ensemble as the Earth system ensemble (or ESE) and we run this for three emission scenarios as described in the next section.

\subsection{Scenarios}

Here we consider 3 future emission pathways, one (SRES A1B) chosen to provide continuity with previous ensembles, and two (RCP8.5 and RCP2.6) chosen to sample the full spread of scenarios used by CMIP5 simulations.

The first of these pathways, the SRES A1B scenario (referred to hereafter as A1B) represents future emissions from greenhouse gases and aerosols under a central nonintervention socio-economic scenario. The implementation of the scenario data to drive the Earth system ensemble is fully described in Collins et al. (2006). The exception is $\mathrm{CO}_{2}$ which, in line with the experimental design, is prescribed as an emission rather than an atmospheric concentration (as described in Booth et al., 2012a).

The representative concentration pathways (RCPs) are a scenario set containing emissions, concentrations and land use trajectories (Van Vuuren et al., 2011). They are intended to be consistent with, and span the plausible range of, the 
current scenario literature and will form the basis of the modelling work that contributes to the fifth assessment report of the IPCC through the CMIP5 exercise (Taylor et al., 2012). The two most extreme pathways are examined here. RCP8.5 lies at the upper end of these pathways and is likely to represent a very high baseline emissions scenario (Van Vuuren et al., 2011). The 8.5 denotes the approximate radiative forcing, in $\mathrm{W} \mathrm{m}^{-2}$, in 2100 (as estimated by the IAMs used to develop the RCP). These concentration pathways will typically be used for atmosphere-ocean general circulation models (AOGCM), and while individual AOGCMs may differ somewhat in the magnitude of modelled radiative forcing, the $\mathrm{RCP}$ value is a good indicator of the typical radiative forcing at the end of the century.

In addition to concentration-driven simulations, core simulations for CMIP5 from earth system models include emissions driven simulations of the 20th century RCP8.5. These are based on the harmonised emissions recommended for CMIP5 (Meinshausen et al., 2011b). Prescribing emissions, rather than concentrations, enables the carbon cycle processes within a GCM to calculate the resulting $\mathrm{CO}_{2}$ concentration changes explicitly. When the subsequent $\mathrm{CO}_{2}$ concentrations are calculated (either in CMIP5 simulations or the ESE) they may result in higher or lower concentrations, and therefore radiative forcing, than the RCP concentration pathway. The comparison with CMIP5 simulations is only done for RCP8.5, as this is the only emission-driven RCP proposed for the CMIP5 exercise; however, harmonised emissions profiles for each RCP do exist (Meinshausen et al., 2011b).

The other RCP examined in the ESE here is RCP2.6. This is intended to produce a radiative forcing in 2100 of around $2.6 \mathrm{~W} \mathrm{~m}^{-2}$. Unlike the other pathways considered here (or more broadly within other sets drawn from SRES scenarios), this pathway is representative of scenarios including extensive and coherent mitigation of greenhouse gas emissions. Radiative forcing peaks at $3 \mathrm{~W} \mathrm{~m}^{-2}$ in the next $40 \mathrm{yr}$ and then declines to $2.6 \mathrm{~W} \mathrm{~m}^{-2}$ by the end of the century. RCP2.6 marks the first aggressive mitigation scenario used extensively by the full Climate Model Intercomparison Project (CMIP). Within the fifth phase of CMIP5, however, this was only done using concentration pathways (Taylor et al., 2012). To reiterate, there is no official emission-driven equivalent multi-model simulations with which to compare the ESE simulations presented here, and in this study emission data for the ESE's RCP2.6 is based on Meinshausen et al. (2011b).

For the two RCP emission-driven experiments simulated by the ESE, the implementation of the scenario-driving data is as described for HadGEM2ES in Jones et al. (2011). There are a number of model processes (typically aerosol species other than sulphates) that are included in the HadGEM2 models but which are not represented with the HadCM3C framework used in the ESE (for example black carbon, biogenic and dust aerosols). The HadCM3C implementation represents natural and industrial emissions of sulphate precursors ( $\mathrm{SO}_{2}$ and DMS) and the sulphate formation and removal pathways and uses background cloud droplet number to account for natural aerosols that are not explicitly represented (Jones et al., 2001). Consequently, where important time variations in non-sulphate aerosols played important roles (such as changes in black carbon emissions in the monsoon region) these simulations would be missing these regional effects. On the global scale, however, historical aerosol changes have been dominated by sulphates, and here the simulations would be expected to be able to capture these sulphate changes. Both the ESE and the HadGEM2ES configuration, described in Jones et al. (2011), represent the dynamical response of vegetation to climate, but differ on how they account for human-induced land cover change. Unlike HadGEM2ES, which imposes a time-varying land use change, the ESE instead uses a time-invariant land use map and so does not capture the temporal variability in human-induced land cover changes. Another aspect where the HadCM3C scenario implementation also differs from Jones et al. (2011), is the treatment of $\mathrm{CO}_{2}$. Similarly to the emission-driven RCP8.5 scenario (Taylor et al., 2012), the HadCM3C prescribes $\mathrm{CO}_{2}$ emission time series rather than concentrations.

Historical simulations from 1860 onwards were performed for every configuration using SRES datasets (Lambert et al., 2013). There are some differences, mainly towards the end of the century, between SRES and RCP historical driving data used in the ESE experiments which could lead to small differences in simulation of the historical climate. For this reason, parallel RCP historical simulations were also performed, initiated from the corresponding SRES 1945 historical state. The SRES future scenario (A1B) was extended from the SRES historical simulations. The RCP2.6 and RCP8.5 (which diverge from 2005) were both extended from the RCP historical simulations (1945-2005) which extended from the first half of the SRES historical simulations (1860-1945). This design was adopted as a precaution, to minimise the climate impact from switching from SRES to RCP historical forcings immediately prior to starting the future scenario simulations. The SRES/RCP historical differences, where they exist, arise either from re-evaluation of the underlying driving data between publication in the SRES and RCP datasets, or due to differences in how these are implemented in the model. The parallel historical simulations ensures that the future SRES A1B response extended from the corresponding SRES historical simulation and the future RCP responses extended from the corresponding RCP historical simulations, in a clean way. Where quantitative $\mathrm{CO}_{2}$ or temperature responses are subsequently quoted, or illustrated, they are done so relative to the corresponding historical extensions, noted above. 

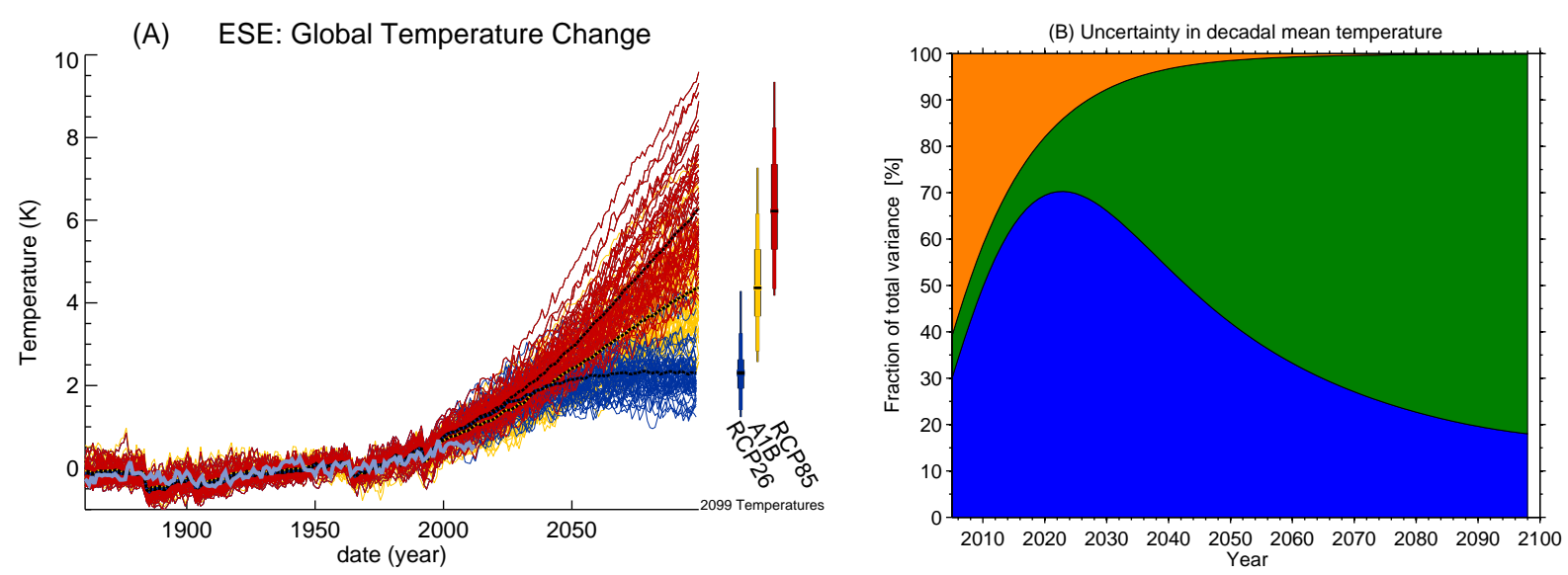

Fig. 1. The global mean temperature response to RCP and SRES scenarios. The projected response to RCP8.5 (red), SRES A1B (yellow) and RCP2.6 (blue) are shown for the ESE ensemble (A) with respect to the 1900 to 2000 baseline. The mean response of each ensemble is shown (bold line). The observations (HadCRUT3) are overplotted in light blue for the historical period. Differences between the mean ensemble response and the observations are evident in the last $10 \mathrm{yr}$, though the observations are still within the ESE distribution. (B) shows the fraction of total variance in decadal global mean surface air temperature projections explained by the scenarios uncertainty (green), model response (blue) and internal variability of the climate system (orange), calculated using the methodology described in Hawkins and Sutton (2009).

\subsection{CMIP5 data}

Data for atmospheric $\mathrm{CO}_{2}$ and global temperature change is available for 10 CMIP5 emission-driven simulations (available for the single RCP8.5 future scenario described above) at the time of writing. These models are: BNU-ESM, CanESM2, GFDL-ESM2, HadGEM2ES, INMCM4, IPSLCM5A-LR, MIROC-ESM, MPI-ESM-LR, MRI-ESM1 and CESM1-BGC. GFDL-ESM2M also exists in the archive (differing from GFDL-ESM2G presented here, only in the ocean physics representation). Given the strong similarity in response between these two configurations, we have considered them here, for global mean $\mathrm{CO}_{2}$ and temperature responses, to be one model. The historical and future scenario used to drive these CMIP5 models is discussed in the previous section. Initial analysis of these CMIP5 emission-driven runs appears in Arora et al. (2013) and Gillett et al. (2013)

\section{Results}

\subsection{Implications for future projections}

As acknowledged in Hawkins and Sutton (2009), "progress in climate science may sometimes broaden rather than narrow uncertainty". They were referring to processes which lie outside current climate modelling systems and the impact that quantification will have for the spread of responses when they are included. Of course the underlying uncertainty has not really increased in any real sense, but rather the increased spread accounts for uncertain processes which previously lay outside the quantifiable framework. The primary example at the time (Hawkins and Sutton, 2009) was written was carbon cycle processes (which were not quantifiable in their analysis due to availability of simulations).

We show that the global mean temperature response, arising from the earth system uncertainties explored in the ESE, gives rise to a broad spread in future responses (Fig. 1a). By 2011, the median ensemble response (RCP scenarios) is already $1.1 \mathrm{~K}$ above the $1900-2000$ baseline climate. In contrast, the observations warm by only $0.5 \mathrm{~K}$ relative to the same baseline, though they still lie within the ESE envelope.

Future temperature projections diverge depending on differences in the emissions scenario, ranging between a $2.3 \mathrm{~K}$ median response above baseline for the aggressive mitigation scenario, to a median response of $6.1 \mathrm{~K}$ for the high-end, business as usual scenario. The spread of these responses is broader than previous concentration-driven GCM simulations, and is discussed further in the following sections.

While the emission-driven ESE simulations point towards a greater projection uncertainty for global mean temperature than previous concentration-driven simulations, they do not imply any fundamental change to the timescale on which different sources of uncertainties play dominant roles. Previous work using concentration-driven GCMs (Hawkins and Sutton, 2009) point to the role that different sources of climate projection uncertainty play, on different timescales. Despite marked increases in future projection spread within the emission-driven ensemble, the ESE produces a remarkably similar picture (Fig. 1b). This figure compares the fraction of the total variance for each decade ahead, explained by the scenario, model response or internal variability variance (details of the method are described in Hawkins and Sutton (2009)). Over the shorter 30-50 yr term, the impact of different emissions scenarios or adoption (or not) of explicit climate mitigation policies is not a significant factor 
Table 1. The distribution of the range of Atmospheric $\mathrm{CO}_{2}(\mathrm{ppm})$ and global temperature $(\mathrm{K})$ responses in ESE, expressed as a change from their pre-industrial values, are given below. These give the lower bound, 10th percentile, 25th percentile, mean, 75th and 90th percentiles and the upper bound for each scenario. The same statistics are also provided for the ensemble if the high-climate sensitivity simulations are excluded from the distribution. The temperatures are based on $5 \mathrm{yr}$ averages at the end of the century, in $\mathrm{Kelvin} \mathrm{The}_{\mathrm{CO}}$ is the 2099 value in ppm. Comparable statistics are provided for concentration-driven SRES A1B.

\begin{tabular}{|c|c|c|c|c|c|c|c|c|c|}
\hline & & $\begin{array}{l}\text { Lower } \\
\text { bound }\end{array}$ & 10 th & $\begin{array}{r}25 \text { th } \\
\text { percentile }\end{array}$ & Median & $\begin{array}{r}75 \text { th } \\
\text { percentile }\end{array}$ & 90th & $\begin{array}{l}\text { Upper } \\
\text { bound }\end{array}$ & $10-90$ \\
\hline \multicolumn{10}{|c|}{ Full ESE range } \\
\hline \multirow[t]{2}{*}{ RCP8.5 } & $\mathrm{CO}_{2}$ & 808 & 864 & 998 & 1106 & 1234 & 1389 & 1596 & 525 \\
\hline & Temp. & 4.0 & 4.2 & 5.1 & 6.1 & 7.2 & 8.1 & 9.3 & 3.9 \\
\hline \multirow[t]{2}{*}{ SRES A1B } & $\mathrm{CO}_{2}$ & 615 & 635 & 723 & 794 & 876 & 972 & 1099 & 367 \\
\hline & Temp. & 2.5 & 2.8 & 3.6 & 4.3 & 5.2 & 6.1 & 7.3 & 3.3 \\
\hline \multirow[t]{2}{*}{$\mathrm{RCP} 2.6$} & $\mathrm{CO}_{2}$ & 387 & 390 & 422 & 449 & 474 & 514 & 574 & 124 \\
\hline & Temp. & 1.3 & 1.5 & 2.0 & 2.3 & 2.6 & 3.2 & 4.1 & 1.7 \\
\hline \multicolumn{10}{|c|}{ ESE range subsampled to exclude climate sensitivities above the CMIP5 range } \\
\hline \multirow[t]{2}{*}{$\mathrm{RCP} 8.5$} & $\mathrm{CO}_{2}$ & 808 & 821 & 959 & 1078 & 1193 & 1374 & 1596 & 553 \\
\hline & Temp. & 4.0 & 4.2 & 4.9 & 5.5 & 6.0 & 6.8 & 8.1 & 2.6 \\
\hline \multirow[t]{2}{*}{ SRES A1B } & $\mathrm{CO}_{2}$ & 615 & 617 & 689 & 771 & 854 & 932 & 1060 & 315 \\
\hline & Temp. & 2.5 & 2.9 & 3.3 & 3.7 & 4.1 & 4.8 & 5.7 & 1.9 \\
\hline \multirow[t]{2}{*}{$\mathrm{RCP} 2.6$} & $\mathrm{CO}_{2}$ & 387 & 402 & 420 & 441 & 465 & 486 & 496 & 84 \\
\hline & Temp. & 1.3 & 1.4 & 1.7 & 2.0 & 2.3 & 2.6 & 3.2 & 1.2 \\
\hline \multicolumn{10}{|c|}{ Concentration-driven ensemble sampling the same atmospheric physics } \\
\hline \multirow[t]{2}{*}{ A1B } & $\mathrm{CO}_{2}$ conc. & & & & 708 & & & & \\
\hline & Temp. & 2.5 & 2.6 & 3.0 & 3.6 & 4.1 & 4.5 & 4.7 & 1.9 \\
\hline
\end{tabular}

in determining the global mean temperature range. Here, the key uncertainties remain in climate response (largely physical feedbacks) and internal variability within the climate system (Fig. 1b). Whilst differences in emissions pathways will not significantly affect temperatures during this period, it should be noted that emissions and mitigation actions over the next $30 \mathrm{yr}$ will be the significant determinant of climate as we move towards the end of the century.

Figure 1b identifies a scenario component, albeit a small contribution, to the total variance in the next $30 \mathrm{yr}$. This is in contrast with the Hawkins and Sutton (2009) assessment where there was little evidence that scenarios make an impact on this time frame. Its presence in the ESE projections more to do with using different implementations of historical forcing datasets in our study (SRES and RCP) than implying that emission-driven runs lead to greater near term scenario uncertainty. The reason this was not seen in Hawkins and Sutton (2009) was that all their simulations shared a common historical forcing dataset. It highlights that near time projections are sensitive to uncertainties in how we represent the past, even if this sensitivity is much smaller than model uncertainty and internal variability.

As we look out to the end of the century, uncertainties concerning future global temperatures are rapidly increasing and differences between different emission scenarios are becoming apparent (Fig. 1a). This is remarkably similar to the comparable analysis on the sources of uncertainty from the concentration-driven paradigm (Fig. 1b compared to Hawkins and Sutton, 2009). Differences in the future socio-economic pathway is still the dominant uncertainty by 2100, despite the increase in model uncertainty exhibited in these simulations. Differences between the ensemble median responses of the two emission pathways which bound the high- and low-end (RCP8.5 and RCP2.6) are larger than the Hawkins and Sutton (2009) range, largely due to the inclusion in this analysis of an emissions pathways which accounts for aggressive mitigation (RCP2.6) and one which lies closer to the upper end of business as usual type scenarios (compared to the upper-most SRES scenario (A2) used in Hawkins and Sutton, 2009).

Although the spread of future responses within the emission paradigm exceeds that documented previously for concentration-driven projections (e.g., Hawkins and Sutton, 2009), adopting smaller future emission profiles is still effective in reducing future temperature uncertainty. The model response uncertainty (using simulated spread between 1090 percentiles) more than doubles from $1.7 \mathrm{~K}$ in RCP2.6 to $3.9 \mathrm{~K}$ in RCP8.5 (Table 1). Figure $1 \mathrm{~b}$ is a useful way of visually representing the contribution of scenario, model and internal variability for future projections over the next century. It is worth noting, though, that what is not characterised here 
is any non-linear dependence of the climate model response on the scenario (such as described in Yip et al., 2011).

\subsection{Responses of the earth system ensemble}

We can break down the plume of future projections (Fig. 1a) into the component atmospheric $\mathrm{CO}_{2}$ and temperature responses for each scenario (Fig. 2). For RCP8.5 the $\mathrm{CO}_{2}$ and temperatures continue to rise during the 20th century, reaching 1106 ppm (ensemble median, 864-1389 ppm 10-90 percentile range, see Table 1 for summary statistics) and $6.1 \mathrm{~K}$ (ensemble median, $4.2-8.1 \mathrm{~K} 10-90$ percentile range). This can be compared with the projections using the SCM MAGICC6 (Meinshausen et al., 2011b) for RCP8.5 (Meinshausen et al., 2011a) based on SCM fits to the climate response (Meinshausen et al., 2011c) of 19 CMIP3 concentrationdriven GCMs and 9 simulations from the Coupled Carbon Cycle Climate Model Intercomparison Project ( $\left.{ }^{4} \mathrm{MIP}\right)$. The ESE projections span the MAGICC6 RCP8.5 $\mathrm{CO}_{2}$ and global temperature responses over the coming century, from the low to the high bounds. In addition, a number of stronger ESE, $\mathrm{CO}_{2}$, and temperature responses lie above this SCM range (something we return to in the next section).

Under aggressive mitigation (RCP2.6) the mean ESE response is $451 \mathrm{ppm}$ (10-90 range: $390-514 \mathrm{ppm})$. The mean temperature response is $2.3 \mathrm{~K}$ (10-90 range: $1.5-3.2 \mathrm{~K}$ ). Comparisons with the SCM projections for the same RCP2.6 scenario (Meinshausen et al., 2011b) show that the median ESE responses tend to be larger by 2100 . Whether this is due to real differences between the ESE and response that CMIP3/ ${ }^{4}$ MIP simulations would have produced under this emission pathway $\left(\mathrm{C}^{4} \mathrm{MIP}\right.$ experiments were previously carried out under the $\mathrm{A} 2$ scenario), or whether it points to difficulties in establishing carbon cycle responses to emission cuts in $\mathrm{CO}_{2}$ using SCMs is an open question. Lowe et al. (2009) illustrated that once temperatures have reached a certain level, atmospheric $\mathrm{CO}_{2}$ concentrations can be remarkably resistant to future reduction, driven by subsequent emission cuts. We would expect similar behaviour in any models presented here, where the simulated land surface has ceased to be a sink by the time of the emission cuts. While the SCM RCP8.5 projections lie within the ESE range, there is a suggestion that the SCM response appears to diverge from ESE projections for the RCP2.6 scenario (where emissions are cut) highlighting that this maybe the case. If so, this highlights the importance of aggressive mitigation scenarios for coupled carbon cycle climate models with which to calibrate SCMs responses, data which is currently not commonly available. As Meinshausen et al. (2011b) note, the RCP scenarios represent a rather stringent test, as the future pathways fall well outside the SRES scenarios that the SCM was calibrated against.

Another evident feature of the RCP2.6 responses is that the inherent uncertainty in ESE climate system representation is much reduced $(1.7 \mathrm{~K} 10-90$ range compared to $3.9 \mathrm{~K}$ in RCP8.5). Even under aggressive mitigation, a small number of models (Fig. 2) suggest a large global mean temperature response is possible (with one model suggesting $\mathrm{CO}_{2}$ could exceed $500 \mathrm{ppm}$, and with 3 models suggesting temperature responses in excess of $4 \mathrm{~K}$ ), implying that high levels of climate change cannot be ruled out - something we return to in the Discussion and Conclusions.

For the SRES A1B scenario (chosen as a central marker scenario within the SRES range) the $2100 \mathrm{CO}_{2}$ and temperature changes fall between RCP2.6 and RCP8.5 (median $794 \mathrm{ppm}$ and 10-90 range 635-972 ppm; median $4.3 \mathrm{~K}, 10$ 90 range 2.8 to $6.1 \mathrm{~K}$ ). Here we can compare the temperature response from the ESE ensemble with that simulated by the equivalent concentration-driven ensemble (Collins et al., 2011). The 2100 temperature response lies between 2.50 and $7.30 \mathrm{~K}$ in $\mathrm{A} 1 \mathrm{~B}$, which compares to the much smaller temperature range for the concentration-driven A1B scenario between 2.50 and $4.65 \mathrm{~K}$ (black and orange box and whisker bars, Fig. 2d). The concentration-driven simulations are broadly in line with estimates from multi-model concentration-driven GCMs (Collins et al., 2011).

The previous IPCC report put the likely range to be between 1.7 and $4.4 \mathrm{~K}$. This upper bound is considerably smaller than that suggested by the emission-driven ESE. This range was largely informed by a combination of available atmosphere-ocean global climate models (AOGCMs) and ranges from SCMs. Knutti and Hegerl (2008) show that a number of sources of information (notably $\mathrm{C}^{4} \mathrm{MIP}$ simulations and Knutti et al., 2003's emulation) were not available to inform the SRES A1B range in previous assessments. Where this information is included for the A2 scenario, this raises the upper bound for $\mathrm{A} 2$ projections by more than would be expected from the difference in emissions alone (by almost $2^{\circ}$ in the case of Knutti et al., 2003). The temperatures presented here for the ESE in SRES A1B are more in line with the underlying uncertainty explored within this latter study.

Lambert et al. (2013) show that the ESE temperature distribution range is broadly consistent with what would be expected from interactions between climate and carbon cycle feedbacks using an SCM tuned to reproduce the atmospheric (Collins et al., 2011), carbon cycle (Booth et al., 2012a), ocean physics (Collins et al., 2007) and sulphur cycle (Lambert et al., 2013) within the component GCM ensembles that make up the ESE. While Lambert et al. (2013) found evidence of interactions between the components, this does not lead to a significant broadening of the expected range. The reasons for the increase to the upper temperature bound, over many previous estimates, are linked to ranges of climate sensitivities and carbon cycle feedbacks and are discussed in more detail in the following two sections.

It is worth highlighting the comparison of the range of future atmospheric $\mathrm{CO}_{2}$ concentration projections with the concentration pathways used for multi-model ensembles. The SRES A1B concentration (dashed red line, Fig. 2c) 


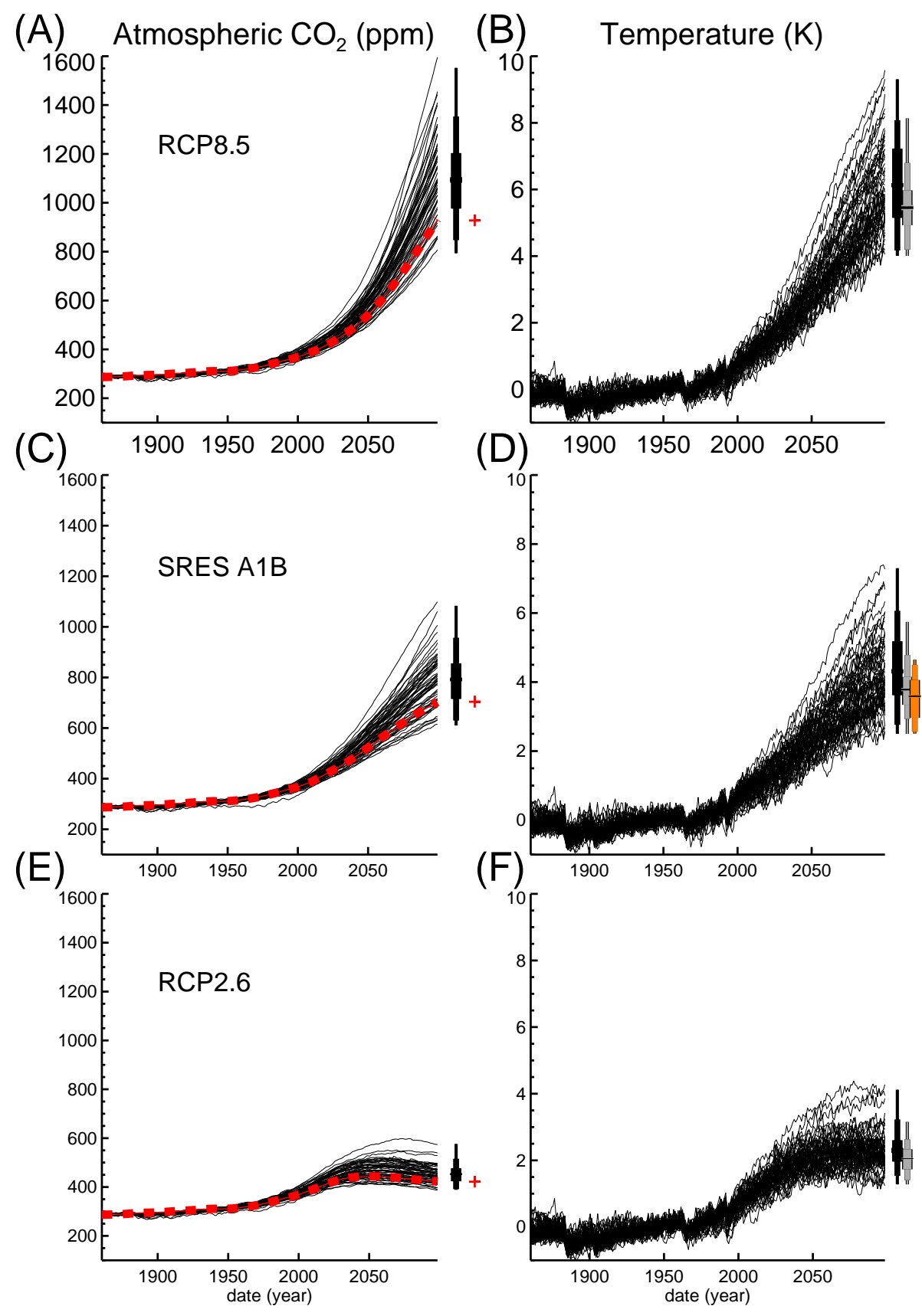

Fig. 2. Simulated $\mathrm{CO}_{2}(\mathbf{A}, \mathbf{C}$ and $\mathbf{E})$ and Temperature (B, D and F) for RCP8.5 (A and B), SRES A1B (C and D) and RCP2.6 (E and F) are shown for the ESE. The concentration profiles (dashed red lines) used by CMIP5 and CMIP3 concentration-driven simulations, are also shown. The 2100 values from these concentration pathways are marked by the red crosses to the right of these panels. The black box and whisker bars (right of panels) indicate the full range (thin line), 10th-90th (medium line) and 25th-75th (thick line) and median (central bar) of the $\mathrm{CO}_{2}$ and global mean temperature at the end of the century. The $\mathrm{CO}_{2}$ value is the annual mean value for 2099 while the global mean is the mean of the last $5 \mathrm{yr}$ (to minimise the impact of internal variability). For temperature panels, grey box and whisker bars illustrate the distribution of responses if climate sensitivity values larger than CMIP5 models are excluded. Also included is the distribution of global mean temperature responses, for the equivalent atmospheric physics response, to the concentration-driven SRES A1B scenario (orange box and whisker bar, based on Collins et al., 2011). 
lies well toward the lower portion of the ESE distribution. This is a concentration pathway based on the standard BernCC configuration, which provided the SRES concentrations based on SRES emissions. The carbon cycle feedbacks of this model are known to be on the low end of the multimodel response (Friedlingstein et al., 2006; Booth et al., 2012a). Under SRES A1B, only 11 of the 57 ESE configurations simulated lower $\mathrm{CO}_{2}$ concentrations by the end of the century compared to the representative pathway/Bern-CC. In contrast, 46 simulations produce larger concentrations than Bern-CC (704 ppm), reaching as high as $1060.4 \mathrm{ppm}$ in 2100 in one of the models. We see a similar picture in both RCPs examined with the ESE, which is also evident when comparing the RCP radiative forcing estimates (Supplement). This is because the SCM used to harmonise emissions with concentrations for the RCPs and MAGICC6.0 (Meinshausen et al., 2011b) is tuned to match the carbon cycle response from Bern-CC.

\subsection{Context within CMIP5 simulations}

The Earth system model ensemble responses illustrated in Figs. 1 and 2 are unique, but it is important to relate them to other available information to provide a context for these climate projections. The advent of emission-driven historical and future (RCP8.5) simulations under the CMIP5 protocol of experiments provides a common basis for this comparison. Before doing so, it is worth considering the spread across CMIP5 simulations (Fig. 3). These simulations represent a diverse range of processes, parameterisations and resolutions, which make it difficult to identify what drives the CMIP5 spread in responses. We can, however, note the role of physical climate responses on the physical and carbon cycle responses across CMIP5. Here, the ordering of CMIP5 future responses for both temperature and $\mathrm{CO}_{2}$, is only partly determined by the magnitude of climate sensitivity (indicated by colours, right-hand panels in Fig. 3), illustrating how important the interactions can be between physical and carbon cycle feedbacks in determining the overall response.

The first aspect of the comparison of global temperature that is immediately evident (Figs. 3a and b) is that while the ESE ensemble explores a broader range of temperature, the ensemble mean is also substantially larger than that of the CMIP5 ensemble mean $(6.1 \mathrm{~K}$ relative to $4.6 \mathrm{~K})$ and does not capture temperature responses below $4 \mathrm{~K}$ for the RCP8.5 scenario. While most CMIP5 models (7 out of 10) fall within the ESE range, 3 models (INM, GFDL-ESM2 and MRI-ESM) explore temperatures below the ESE's lower bound (3.1, 3.4 and $3.3 \mathrm{~K}$, respectively). The reasons for these differences at both the high and low end relate to a larger ensemble size used to sample this range and also relate to differences in physical climate feedbacks and carbon cycle responses between the two ensembles. These are discussed later.

In contrast, when comparing future atmospheric $\mathrm{CO}_{2}$ concentrations (Fig. $3 \mathrm{c}$ and d), the ESE is able to encompass almost the full range of the CMIP5 projections (ranging from just above MRI-ESM on the lower bound, up past MIROCESM on the upper bound). In addition, the ESE ensemble simulates responses that lie above the CMIP5 range. There are reasons why we would expect this. Recent analysis of CMIP5 carbon cycle responses (Arora et al., 2013) suggests that the upper bound of carbon cycle sensitivity is likely to be smaller than in $\mathrm{C}^{4} \mathrm{MIP}$. Uncoupled experiments for the ESE which would enable us to make direct comparisons are not currently available. One factor which may contribute to this reduced upper bound is that the model which previously marked the $\mathrm{C}^{4} \mathrm{MIP}$ upper bound, HadCM3L (the lower resolution version of the standard HadCM $3 \mathrm{C}$ configuration, perturbed in the ESE), was not submitted to CMIP5. So we would expect a larger upper bound in the ESE compared to CMIP5 on this basis alone. In addition, perturbations to HadCM3C span most of the $\mathrm{C}^{4} \mathrm{MIP}$ range and sample a number of stronger carbon cycle responses than the standard HadCM3C configuration (Booth et al., 2012a), which will also contribute to the larger upper bound. It is worth noting that the carbon cycle spread is not centred around a high carbon feedback model variant. Fifty-one (51) out of 57 ESE simulations lead to smaller atmospheric $\mathrm{CO}_{2}$ concentrations in 2100 than the standard HadCM3C, despite many of these configurations having larger climate sensitivities.

To understand why the ESE and CMIP5 explore different parts of the future range, it is useful to compare the climate sensitivities of the models which make up these ensembles (Fig. 3e). The most obvious difference between the two are the 5 atmospheric configurations with climate sensitivities above the most sensitive CMIP5 model (MIROCESM). Plotting only those ESE configurations with sensitivities within the CMIP5 climate sensitivity range (grey and blue lines, Fig. 3a) excludes most of the high-temperature responses within the ESE ensemble. So differences in the upper bound of climate sensitivity appear to explain most, but not all, of the temperature responses above the CMIP5 range. Even if we were able to exclude those models with larger climate sensitivities, for example through better observation constraints, there would still be a small number of configurations that simulate atmospheric $\mathrm{CO}_{2}$ concentrations well above the CMIP5 range, which even with the smaller upper climate sensitivity values lead to stronger warming. This is related to the inclusions of models with stronger carbon cycle feedbacks than CMIP5 (see discussion above). Excluding the high-sensitivity simulations leads to a slightly lower median ESE $\mathrm{CO}_{2}$ concentration by 2100 (1078 ppm compared to $1106 \mathrm{ppm}$ in the full ensemble) as climate-carbon cycle feedbacks respond to smaller temperature changes across the ensemble. However, inclusion of models with high-climate sensitivities appears to have only small impact on the range of atmospheric $\mathrm{CO}_{2}$ for business as usual scenarios (1090 range actually increases for RCP8.5, see Table 1). This is in contrast with the mitigation scenario where the climate 

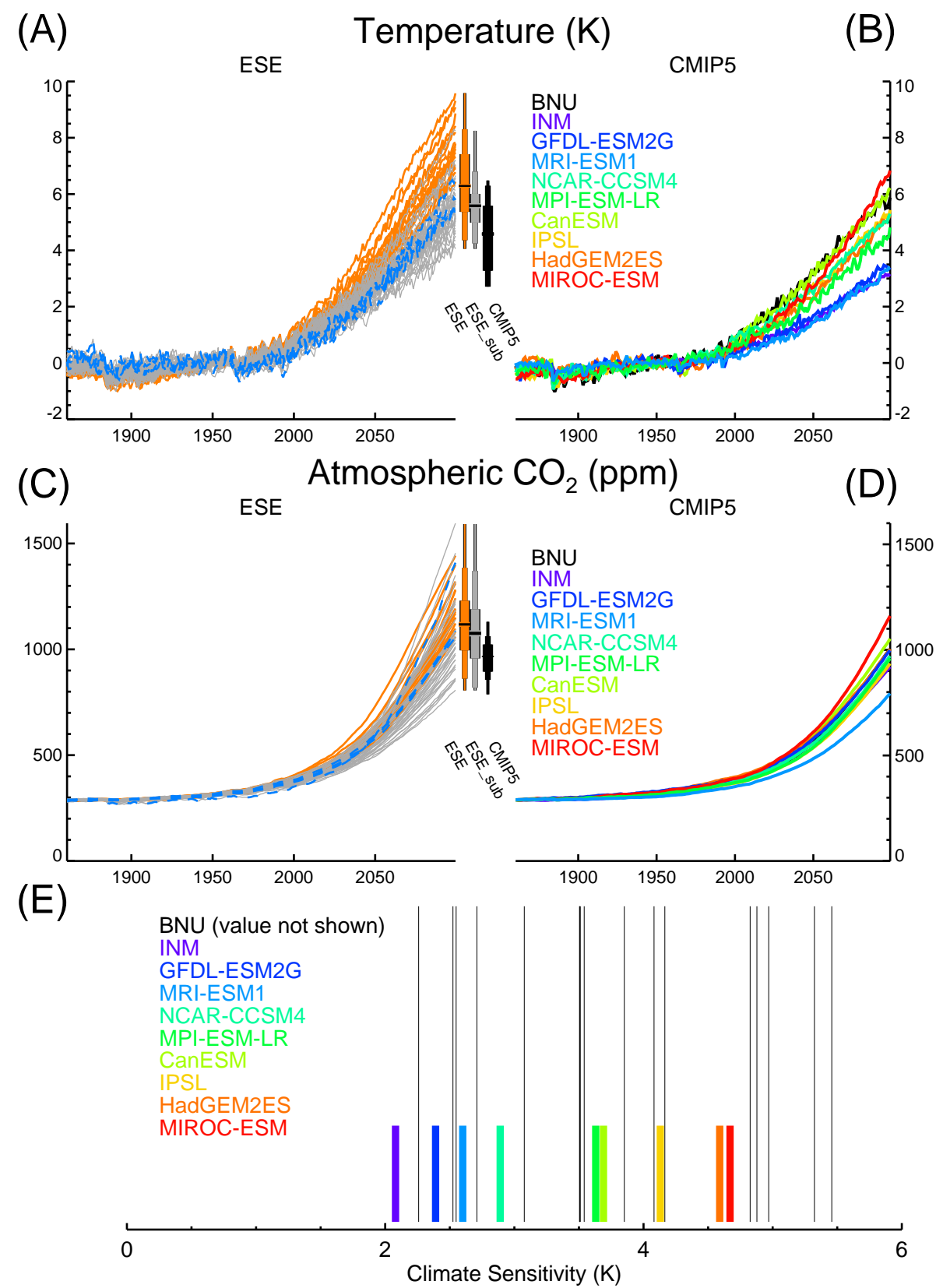

Fig. 3. Comparison of ESE and CMIP5 responses. The figure shows projected ESE (A and C) and CMIP5 emisRCP85 (B and D) responses for global mean temperature $(\mathbf{A}$ and $\mathbf{B})$ and atmospheric $\mathrm{CO}_{2}(\mathbf{C}$ and $\mathbf{D})$. For the ESE projections, colours are used to distinguish between models with climate sensitivities above $4.5 \mathrm{~K}$ (orange) and those below (grey). The 4 ESE configurations with the lowest climate sensitivity configuration are overplotted (dashed blue). The box and whisker bars indicate the full range (thin line), 10th-90th (medium line) and 25th-75th (thick line) and median (central bar). The Box and Whiskers bars present the spread for the full ESE range (orange) and the ESE range when high-climate sensitivities are excluded (grey) and the CMIP5 range (black). The colours for the CMIP5 projections (B and D) indicate the relative magnitude of climate sensitivity of each simulation (based on values in E). (E) shows the ranking for CMIP5 model (short, coloured bars) with estimates for the 17 Atmospheric configurations which make up the ESE ensemble (thin black bars). The original 68 members of the ESE ensemble combines each atmospheric configuration with 4 different combinations of land carbon cycle, ocean physics and aerosol configuration (Lambert et al., 2013). The resultant 57 members (after 11 combinations were rejected based on 1860 climate, Lambert et al., 2013) therefore contains multiple incidences (up to 4) of each of these climate sensitivities (thin black bars). The climate sensitivities were estimated from $1 \% \mathrm{CO}_{2}$ ramp experiments for the perturbed HadCM3 configurations (Collins et al., 2011) and CMIP5 estimates are based on Andrews et al. (2012). The exceptions to this are values for NCAR's CCSM4 (T. Andrews, personal communications, based on same methodology, 2012) and BNU for which data was not available at the time of writing. Where the CMIP5 configuration used to estimate the climate sensitivity excluded carbon cycle processes, we make the assumption that the inclusion of these carbon cycle processes in this analysis does not change the climate sensitivity. 
sensitivity does have a larger impact on the range of $\mathrm{CO}_{2}$ responses.

Returning to the 3 CMIP5 models with low magnitudes of global warming, these lie outside the distribution of modelled ESE responses presented here. It is not the case that the component of these responses lie outside the ESE model range due to carbon cycle processes (the ESE spans the CMIP5 atmospheric $\mathrm{CO}_{2}$ concentrations, Fig. 3), nor is it the case that these models are outside the climate sensitivity range (only INM lies below the ESE range of climate sensitivities, Fig. 3e). The experimental design (a latin hypercube, see Lambert et al., 2013) is set up to evenly span ESE response space rather than specifically explore the corners (e.g. high (low) carbon cycle feedback configurations combined with high (low) atmospheric feedbacks). The ESE does not sample this low carbon cycle feedback, or low climate sensitivity corner. This is illustrated (Fig. 3, dashed blue lines) by showing the $\mathrm{CO}_{2}$ and temperature responses of $4 \mathrm{ESE}$ configurations using the low-climate sensitivity, where carbon cycle combinations lead to mid/high atmospheric $\mathrm{CO}_{2}$ concentrations. If there was only a single CMIP5 model in this particular low-carbon cycle, low sensitivity part of model space, we could perhaps assume that this was just chance sampling of possible model processes. The fact that there are 3 CMIP5 models below the ESE range suggests that it is unlikely to be the lower limit of all possible coupled carbon climate model responses. Therefore, is it more probable that there are structural differences in HadCM3C which limits its ability to capture the low end of possible emission-driven responses.

\section{Discussion and conclusions}

Sampling uncertainty from the emission perspective, rather than concentration, can lead to a very broad range of future atmospheric concentrations and resulting temperature changes. It is important to note here that no attempt has been made to formally assess which of these projections are more likely. This is an important step before information from these kinds of simulations can be most effectively used in understanding future climate change. For example, a number of the ESE members diverge from observed $\mathrm{CO}_{2}$ values in present-day. This is also evident for CMIP5's MRI-ESM, which underestimates the observed trend. Uncertainties in the historical carbon emissions (which are dominated by land use change rather than fossil fuel emission estimates), not sampled in the ESE will first need to be accounted for before we can use these present-day values to weight the models. One of the primary motivations for developing the ESE simulations presented here is that they will provide a framework with which to explore simulated and observed climate changes. Cox et al. (2013) point to metrics via which we can relate observable properties of the climate system to aspect of the future projections. The strength of the ESE is that it simulates broad ranges of responses within which we can explore these and other relationships, and these simulations are expected to help inform this future work.

In the previous section we touched on the relationship between climate sensitivity and the ESE temperature responses. We can use this to illustrate the implication for what we could say if we could narrow the climate sensitivity range. The previous IPCC assessment estimated the likely range of climate sensitivity as being between 1.5 and $4.5 \mathrm{~K}$. Work done to constrain the range based on observational metrics suggests that it is very unlikely that the value of the real world lies below this range. However, as the last assessment notes: "Values substantially higher than $4.5 \mathrm{~K}$ cannot be excluded, but agreement with observations is not as good for those values". The relationship between high-climate sensitivity and temperature response in the ESE implies that if we can constrain the climate sensitivity of the real world below this value, then we can exclude many of the warm outliers. In particular, this would reduce the worst case temperature response under RCP2.6, from 4.1 to $3.2 \mathrm{~K}$. For the high-end RCP8.5, rejecting high-sensitivity models would lead to the 90th percentile, reducing from 8.1 to $6.8 \mathrm{~K}$. Knutti and Hegerl (2008), in their review of climate sensitivity, show that it is very difficult to narrow this upper range despite drawing information from a very broad range of sources. There are more recent suggestions (Sexton et al., 2012; Sexton and Murphy, 2012) whose systematic comparisons of modelled and observed climate may provide a stronger constraint than previously thought, but this question is still very much an open one (Skinner, 2012). These results highlight why it is so important to narrow down the range of climate sensitivity consistent with the real world.

We find interesting differences in the behaviour of the carbon cycle between different scenarios. There is a relationship between high-climate sensitivity and high-atmospheric $\mathrm{CO}_{2}$ in the RCP2.6 (presumably acting via larger climatecarbon cycle feedbacks). The relationship is much weaker under RCP8.5 where, for example, the largest $\mathrm{CO}_{2}$ response is not linked to these high-climate sensitivity configurations. This means that different carbon cycle configurations determine the high-end $\mathrm{CO}_{2}$ response, depending on the future emission pathways. This implies that we will need to find constraints for different aspects of carbon cycle to narrow future uncertainties depending on the future scenario. Much more work will need to be done on this, but having an ensemble of this kind will enable us to identify and explore mechanisms behind these questions.

We have shown that sampling uncertainties arising from atmospheric physics, land carbon cycle, ocean physics and sulphur cycle can lead to a broad range of future atmospheric $\mathrm{CO}_{2}$ and temperature responses for 3 future emissions scenarios. Lambert et al. (2013) demonstrate that for A1B this range is largely consistent with what would be expected from energy balance and simple carbon cycle assumptions alone, based on information from the component atmospheric physics (Collins et al., 2011), land carbon cycle 
(Booth et al., 2012a), ocean physics (Collins et al., 2007) and sulphur cycle (Lambert et al., 2013). Interactions between the components represented a quantifiable but smaller contribution to the overall spread (Lambert et al., 2013). Our ensemble simulates a range of future $\mathrm{CO}_{2}$ concentrations which span CMIP5 RCP8.5 emission-driven runs, and extends above CMIP5 to capture larger responses. For temperature, the ESE range is both broader and offset to larger values. The differences in the upper bound can be linked both to differences in the upper-range climate sensitivities sampled, and to a number of configurations which produce strong $\mathrm{CO}_{2}$ responses. Differences on the lower temperature bound between CMIP5 and ESE suggest that there may be structural differences between the two ensembles, which limits the ESE's ability to capture low temperature responses for emission-driven simulations.

If the analysis previously done with concentration-driven GCM ensembles (Hawkins and Sutton, 2009) is compared to that done in this paper, similar inferences of the relative importance of different climate uncertainties (for different timescales) also holds for the emission-driven paradigm. We find that differences between the emission-driven scenarios considered here, remain small over the next $30-50 \mathrm{yr}$, but become the dominant uncertainty by the end of the century. It remains an open question for the reader whether we consider each of these scenarios to be equally realisable over the next century. It is worth noting that the different sources of uncertainty, which play a role in both this and the previous analysis on timescales, are largely based on greenhouse gasdriven scenarios. Emerging understanding of the importance of other drivers, such as aerosols (Booth et al., 2012b) or land use changes, may mean that there will be a larger dependence on the scenario earlier in the century (than estimated here or in Hawkins and Sutton, 2009), particularly as we move away from global mean responses and consider regional changes.

Overall, assessing the relative importance of climate uncertainties for different timescales confirms much of the same analysis originally done with concentration-driven AOGCMs. The range of projections arising from this ensemble of emission-driven Earth system models is broader than previous concentration-driven estimates. The atmospheric $\mathrm{CO}_{2}$ and global temperature responses span the range of RCP8.5 Simple Climate Model projections, calibrated against previous $\mathrm{C}^{4} \mathrm{MIP} / \mathrm{CMIP} 3$ simulations. A number of simulations also suggest larger responses than this SCM estimate, which is linked to larger climate sensitivities sampled more frequently in the atmospheric physics (Collins et al., 2011) than CMIP3 and a small number of stronger carbon cycle responses than $\mathrm{C}^{4} \mathrm{MIP}$ (Booth et al., 2012a). These simulations provide a framework within which we can look for observable properties to provide indications of which simulations are more plausible.

\section{Supplementary material related to this article is available online at: http://www.earth-syst-dynam.net/4/ 95/2013/esd-4-95-2013-supplement.pdf.}

Acknowledgements. The authors Ben Booth, Dan Bernie, Doug McNeall, John Caesar and David Sexton were supported by the Joint DECC/Defra Met Office Hadley Centre Climate Programme (GA01101). The RCP2.6 experiments were made possible through the AVOID programme (DECC and Defra) under contract GA0215. Ed Hawkins is supported by NERC and the National Centre for Atmospheric Science (NCAS). We would like to acknowledge Spencer Liddicott and Patricia Cadule for providing atmospheric $\mathrm{CO}_{2}$ concentrations for HadGEM2ES and IPSL (respectively) and Tim Andrews for providing climate sensitivity estimates for NCAR's CESM, based on the approach taken in his paper. We are also grateful for useful discussions with Chris Jones during the writing of this manuscript. We acknowledge the World Climate Research Programme's Working Group on Coupled Modelling, which is responsible for CMIP, and we thank the climate modelling groups (listed in Sect. 2.1.2 of this paper) for producing and making available their model output. For CMIP the US Department of Energy's Program for Climate Model Diagnosis and Intercomparison provides coordinating support and led development of software infrastructure in partnership with the Global Organization for Earth System Science Portals.

Edited by: S. Smith

\section{References}

Andrews, T., Gregory, J. M., Webb, M. J., and Taylor, K. E.: Forcing, feedbacks and climate sensitivity in CMIP5 coupled atmosphere-ocean climate models, Geophys. Res. Lett., 39, L09712, doi:10.1029/2012GL051607, 2012.

Arora, V. K., Boer, G. J., Friedlingstein, P., Eby, M., Jones, C. D., Christian, J. R., Bonan, G., Bopp, L., Brovkin, V., Cadule, P., Hajima, T., Ilyina, T., Lindsay, K., Tjiputra, J. F., and Wu, T.: Carbon-concentration and carbon-climate feedbacks in CMIP5 Earth system models, J. Climate, in press, 2013.

Booth, B. B. B., Jones, C. D., Collins, M., Totterdell, I. J., Cox, P. M., Sitch, S., Huntingford, C., Betts, R. A., Harris, G. R., and Lloyd, J.: High sensitivity of future global warming to land carbon cycle processes, Environ. Res. Lett., 7, 024002, doi:10.1088/1748-9326/7/2/024002, 2012a.

Booth, B. B. B., Dunstone, N. J., Halloran, P. R., Andrews, T., and Bellouin, N.: Aerosols implicated as a prime driver of twentiethcentury north atlantic climate variability, Nature, 484, 228-232, doi:10.1038/nature10946, 2012b.

Brierley, C. M., Collins, M., and Thorpe, A. J.: The impact of perturbations to ocean-model parameters on climate and climate change in a coupled model, Clim. Dynam., 34, 325-343, doi:10.1007/s00382-008-0486-3, 2010.

Collins, M., Booth, B. B. B., Harris, G. R., Murphy, J. M., Sexton, D. M. H., and Webb, M. J.: Towards quantifying uncertainty in transient climate change, Clim. Dynam., 27, 127-147, 2006. 
Collins, M., Brierley, C. M., MacVean, M., Booth, B. B. B., and Harris, G. R.: The sensitivity of the rate of transient climate change to ocean physics perturbations, J. Climate, 20, 23152320, 2007.

Collins, M., Booth, B. B. B., Bhaskaran, B., Harris, G. R., Murphy, J. M., Sexton, D. M. H., and Webb, M. J.: Climate model errors, feedbacks and forcings: a comparison of perturbed physics and multi-model ensembles, Clim. Dynam., 36, 1737-1766, doi:10.1007/s00382-010-0808-0, 2011.

Cox, P. M. and Stephenson, D. B.: A changing climate for prediction, Science, 317, 207-208, 2007.

Cox, P. M., Pearson, D., Booth, B. B. B., Friedlingstein, P., Huntingford, C., Jones, C. D., and Luke, C. M.: Carbon dioxide variability constrains the sensitivity of tropical carbon to climate change, Nature, 494, 341-344, doi:10.1038/nature11882, 2013.

Hawkins, E. and Sutton, R.: The potential to narrow uncertainty in regional climate predictions, B. Am. Meteorol. Soc., 90, 1095, doi:10.1175/2009BAMS2607.1, 2009.

Friedlingstein, P., Cox, P., Betts, R., Bopp, L., von Bloh, W., Brovkin, V., Cadule, P., Doney, S., Eby, M., Fung, I., Bala, G., John, J., Jones, C., Joos, F., Kato, T., Kawamiya, M., Knorr, W., Lindsay, K., Matthews, H. D., Raddatz, T., Rayner, P., Reick, C., Roeckner, E., Schnitzler, K., Schnur, R., Strassman, K., Weaver, A. J., Yoshikawa, C., and Zeng, N.: Climate-carbon cycle feedback analysis: Results from the $\mathrm{C}^{4} \mathrm{MIP}$ model intercomparison, J. Climate, 19, 3337-3353, 2006.

Gillett, N. P., Arora, V. K., Matthews, D., and Allen, M. R.: Constraining the ratio of global warming to cumulative $\mathrm{CO}_{2}$ emissions using CMIP5 simulations, J. Climate, in review, 2013.

IPCC: Climate change 2007: The Physical Science Basis, Contribution of Working Group I to the Fourth Assessment Report of the Intergovernmental Panel on Climate Change, Cambridge Univ. Press, Cambridge, 2007.

Jones, A., Roberts, D., Woodage, M., and Johnson, C.: Indirect sulphate aerosol forcing in a climate model with an interactive sulphur cycle, J. Geophys. Res., 106, 20293-20310, 2001.

Jones, C. D., Hughes, J. K., Bellouin, N., Hardiman, S. C., Jones, G. S., Knight, J., Liddicoat, S., O'Connor, F. M., Andres, R. J., Bell, C., Boo, K.-O., Bozzo, A., Butchart, N., Cadule, P., Corbin, K. D., Doutriaux-Boucher, M., Friedlingstein, P., Gornall, J., Gray, L., Halloran, P. R., Hurtt, G., Ingram, W. J., Lamarque, J.-F., Law, R. M., Meinshausen, M., Osprey, S., Palin, E. J., Parsons Chini, L., Raddatz, T., Sanderson, M. G., Sellar, A. A., Schurer, A., Valdes, P., Wood, N., Woodward, S., Yoshioka, M., and Zerroukat, M.: The HadGEM2-ES implementation of CMIP5 centennial simulations, Geosci. Model Dev., 4, 543-570, doi:10.5194/gmd-4-543-2011, 2011.

Knutti, R. and Hegerl, G.: The equilibrium sensitivity of earth's temperature to radiation changes, Nat. Geosci., 1, 735-743, 2008.

Knutti, R., Stocker, T. F., Joos, F., and Plattner, G.-K.: Probabilistic climate change projections using neural networks, Clim. Dynam., 21, 257-272, doi:10.1007/s00382-003-0345-1, 2003.

Lambert, F. H., Harris, G. R., Collins, M., Murphy, J. M., Sexton, D. M. H., and Booth, B. B. B.: Interactions between perturbations to different Earth system components simulated by a fully-coupled climate model, Clim. Dynam., doi:10.1007/s00382-012-1618-3, in press, 2013.
Lee, T. C. K., Zwiers, F. W., Zhang, X., and Tsao, M.: Evidence of Decadal Climate Prediction Skill Resulting from Changes in Anthropogenic Forcing, J. Climate, 19, 5305-5318, doi:10.1175/JCLI3912.1, 2006.

Lowe, J. A., Huntingford, C., Raper, S. C. B., Jones, C. D., Liddicoat, S. K., and Gohar, L. K.: How difficult is it to recover from dangerous levels of global warming?, Environ. Res. Lett., 4, 014012, doi:10.1088/1748-9326/4/1/014012, 2009.

Meinshausen, M., Raper, S. C. B., and Wigley, T. M. L.: Emulating coupled atmosphere-ocean and carbon cycle models with a simpler model, MAGICC6 - Part 1: Model description and calibration, Atmos. Chem. Phys., 11, 1417-1456, doi:10.5194/acp11-1417-2011, 2011a.

Meinshausen, M., Smith, S. J., Calvin, K. V., Daniel, J. S., Kainuma, M., Lamarque, J. F., Matsumoto, K., Montzka, S. A., Raper, S. C. B., Riahi, K., Thomson, A. M., Velders, G. J. M., and van Vuuren, D.: The RCP greenhouse gas concentrations and their extension from 1765 to 2300 , Climatic Change, 109, 213-241, doi:10.1007/s10584-011-0156-z, 2011b.

Meinshausen, M., Wigley, T. M. L., and Raper, S. C. B.: Emulating atmosphere-ocean and carbon cycle models with a simpler model, MAGICC6 - Part 2: Applications, Atmos. Chem. Phys., 11, 1457-1471, doi:10.5194/acp-11-1457-2011, 2011c.

Murphy, J. M., Sexton, D. M. H., Barnett, D. N., Jones, G. S., Webb, M. J., Collins, M., and Stainforth, D. J.: Quantification of modelling uncertainties in a large ensemble of climate change simulations, Nature, 430, 768-772, 2004.

Murphy, J. M., Booth, B. B. B., Collins, M., Harris, G. R., Sexton, D. M. H., and Webb, M. J.: A methodology for probabilistic predictions of regional climate change from perturbed physics ensembles, Philos. T. Roy. Soc. A, 365, 1993-2028, 2007.

Murphy, J. M., Sexton, D. M. H., Jenkins, G. J., Boorman, P. M., Booth, B. B. B., Brown, C. C., Clark, R. T., Collins, M., Harris, G. R., Kendon, E. J., Betts, R. A., Brown, S. J., Howard, T. P., Humphrey, K. A., McCarthy, M. P., McDonald, R. E., Stephens, A., Wallace, C., Warren, R., Wilby, R., and Wood, R. A.: UK Climate Projections Science Report: Climate change projections, available at: http://ukclimateprojections.defra.gov.uk/22566, last access: 6 September 2012, Met Office Hadley Centre, Exeter, UK, 2009.

Nakicenovic, N., Alcamo, J., Davis, G., Vries, B. D., Fenhann, J., Gaffin, S., Gregory, K., Grubler, A., Jung, T. Y., and La Rovere, T. K., Michaelis, L., Moria, S., Morita, T., Pepper, W., Pitcher, H., Price, L., Raihi, K., Roehrl, A., Rogner, H. H., Sankovski, A., Schlesinger, M., Shukla, P., Smith, S., Swart, R., van Rooijen, S., Victor, N., and Dadi, Z.: IPCC Special Report on Emission Scenarios, Cambridge, 2000.

Reichler, T. and Kim, J.: Uncertainties in the climate mean state of global observations, reanalyses, and the GFDL climate model, J. Geophys. Res., 113, D05106, doi:10.1029/2007JD009278, 2008.

Sexton, D. M. H. and Murphy, J. M.: Multivariate prediction using imperfect climate models Part II: robustness of methodological choices and consequences for climate sensitivity, Clim. Dynam., 38, 2543-2558, doi:10.1007/s00382-011-1209-8, 2012.

Sexton, D. M. H., Murphy, J. M., Collins, M., and Webb, M. J.: Multivariate probabilistic projections using imperfect climate models Part I: outline of methodology, Clim. Dynam., 38, 2513-2542, doi:10.1007/s00382-011-1208-9, 2012. 
Skinner, L.: A Long View on Climate Sensitivity, Science, 24, $917-$ 919, doi:10.1126/science.1224011, 2012.

Taylor, K., Stouffer, R., and Meeh, G.: An overview of cmip5 and the experiment design, B. Am. Meteorol. Soc., 93, 485-498, doi:10.1175/BAMS-D-11-00094.1, 2012.

van Vuuren, D. P., Edmonds, J. A., Kainuma, M., Riahi, K., Thomson, A. M., Hibbard, K., Hurtt, G. C., Kram, T., Krey, V., Lamarque, J.-F., Masui, T., Meinshausen, M., Nakicenovic, N., Smith,
S. J., and Rose, S.: The representative concentration pathways: an overview, Climatic Change, 109, 5-31, doi:10.1007/s10584011-0148-z, 2011.

Yip, S., Ferro, C. A. T., Stephenson, D. B., and Hawkins, E.: A Simple, Coherent Framework for Partitioning Uncertainty in Climate Predictions, J. Climate, 24, 4634-4643, 2011. 